Seiko Ito $\cdot$ Emiko Noguchi $\cdot$ Masanao Shibasaki

Kimiko Yamakawa-Kobayashi • Hideki Watanabe

Tadao Arinami

\title{
Evidence for an association between plasma platelet-activating factor acetylhydrolase deficiency and increased risk of childhood atopic asthma
}

Received: November 15, 2001 / Accepted: December 3, 2001

\begin{abstract}
Platelet-activating factor (PAF), which has been implicated in the pathophysiology of inflammation in asthma, is degraded and inactivated by PAF acetylhydrolase (PAFAH). Approximately $4 \%$ of the Japanese population lacks plasma PAFAH due to a loss-of-function variant (Val279Phe) in the $P A F A H$ gene. Although lack of PAFAH activity is thought to be a risk factor for asthma, there are conflicting findings concerning association between the Val279Phe variant and asthma. In this study, we conducted transmission disequilibrium tests of 118 Japanese parent-child trios identified through mite-sensitive atopic asthmatic children. A case-control study was also carried out. The Phe279/Phe279 genotype was found more frequently in children with atopic asthma $(13 \%)$ than in their parents $(6 \%)$ or in controls $(4 \%)$. Results of the genotypic transmission test were significant, and the Phe279/ Phe279 genotype was transmitted preferentially to asthmatic children. Our data support an association between deficiency in PAFAH activity and atopic asthma.
\end{abstract}

Key words Asthma - Association - Genetic polymorphism . Platelet-activating factor acetylhydrolase - Transmission disequilibrium test

\section{Introduction}

Platelet-activating factor (PAF) is a phospholipid with a variety of biological functions, including signaling and activation of proinflammatory cells such as platelets and neu-

S. Ito $\cdot$ E. Noguchi $\cdot$ K. Yamakawa-Kobayashi $\cdot$ H. Watanabe

T. Arinami $(\square)$

Department of Medical Genetics, Institute of Basic Medical

Sciences, Institute of Clinical Medicine, University of Tsukuba, 1-1-1

Tennoudai, Tsukuba 305-8575 Japan

Tel. +81-298-533352; Fax +81-298-533333

e-mail: tarinami@md.tsukuba.ac.jp

E. Noguchi $\cdot$ M. Shibasaki

Department of Pediatrics, Institute of Basic Medical Sciences,

University of Tsukuba, Tsukuba, Japan trophils (Benveniste et al. 1982; Prescott et al. 1990). PAF has been reported to alter platelet-dependent bronchoconstriction (Miwa et al. 1988), and increased PAF levels have been observed during acute asthma attacks (Hsieh and $\mathrm{Ng}$ 1993; Tsukioka et al. 1996). Release and degradation of PAF is controlled by intracellular and plasma PAF acetylhydrolases (PAFAH, or PLA2G7, an alternative gene symbol). Plasma PAFAH levels vary in association with physiologic and pathologic conditions such as pregnancy, parturition, hyperlipidemia, cardiovascular diseases, stroke, rheumatoid arthritis, sepsis, and asthma, and acquired deficiency of plasma PAFAH has been reported in patients with bronchial asthma (Tsukioka et al. 1993). Approximately $4 \%$ of the Japanese population lacks plasma PAFAH activity, and most instances are due to a loss-offunction variant (Val279Phe) of the PAFAH gene (Stafforini et al. 1996). Thus, the Val279Phe variant is useful for examining the causative relation between plasma PAFAH deficiency and asthma, although this loss-offunction variant has been found in the Japanese, but not in the Caucasian population. Findings concerning this association are inconsistent: the Val279Phe mutation was found to be associated with severe asthma in one study (Stafforini et al. 1999), but not in another study (Satoh et al. 1999). Both studies examined the association in populations of Japanese adults. To elucidate the role of the Val279Phe polymorphism for the development of asthma, we conducted a transmission disequilibrium test (TDT) and case control study in the Japanese population.

\section{Subjects and methods}

Probands of the families were asthmatic children who visited the Pediatric Allergy Clinic of the University Hospital of Tsukuba (Japan). A full verbal and written explanation of the study was given to all family members interviewed, and 144 families (476 individuals) gave informed consent and participated in the study. The mean age of the probands and their siblings was 10.6 years (range, 3 to 29 
Table 1. Genotypic distribution of the Val279Phe polymorphism of the PAFAH gene

\begin{tabular}{|c|c|c|c|c|c|c|}
\hline & \multicolumn{4}{|c|}{$\begin{array}{l}\text { Genotype counts } \\
\text { (frequencies) }\end{array}$} & \multicolumn{2}{|c|}{$\begin{array}{l}\text { Allele counts } \\
\text { (frequencies) }\end{array}$} \\
\hline & $\mathrm{n}$ & $\mathrm{Val} / \mathrm{Val}$ & Val/Phe & $\mathrm{Phe} / \mathrm{Phe}^{\mathrm{a}}$ & Val & $\mathrm{Phe}^{\mathrm{b}}$ \\
\hline Controls (adults) & 188 & $117(0.62)$ & $63(0.34)$ & $8(0.04)$ & $297(0.79)$ & $79(0.21)$ \\
\hline Controls (children) & 142 & $92(0.65)$ & $44(0.31)$ & $6(0.04)$ & $228(0.80)$ & $56(0.20)$ \\
\hline Fathers & 118 & $58(0.49)$ & $54(0.46)$ & $6(0.05)$ & $170(0.72)$ & $66(0.28)$ \\
\hline Mothers & 118 & $61(0.52)$ & $50(0.42)$ & $7(0.06)$ & $172(0.73)$ & $64(0.27)$ \\
\hline Asthmatic children & 118 & $60(0.51)$ & $43(0.36)$ & $15(0.13)$ & $163(0.69)$ & $73(0.31)$ \\
\hline \multicolumn{7}{|c|}{$\begin{array}{l}\text { PAFAH, platelet-activating factor acetylhydrolase; OR, odds ratio; CI, confidence interval } \\
\text { a } P=0.006(\mathrm{OR}=3.3,95 \% \text { CI } 1.3-8.0) \text { between asthmatic children and adult controls; } P=0.02(\mathrm{OR}=3.3 \text {, } \\
95 \% \text { CI } 1.2-8.8) \text { between asthmatic children and nonasthmatic and nonatopic child controls; and } P=0.02 \\
(\mathrm{OR}=2.5,95 \% \text { CI } 1.2-5.4) \text { between asthmatic children and parents, when comparisons were made between } \\
\text { Phe/Phe and Val/Val }+ \text { Val/Phe } \\
\text { b } P=0.007(\mathrm{OR}=1.7,95 \% \text { CI } 1.2-2.4) \text { between asthmatic children and adult controls, } P=0.004(\mathrm{OR}=1.8, \\
95 \% \text { CI } 1.2-2.7) \text { between asthmatic children and nonasthmatic and nonatopic child controls, and } P=0.03 \\
(\mathrm{OR}=1.4,95 \% \text { CI } 1.0-2.0) \text { between parents and controls }\end{array}$} \\
\hline
\end{tabular}

years); the mean age of the parents was 40 years (range, 26 to 72 years). Criteria used to identify asthma patients have been described previously (Yokouchi et al. 2000).

The families examined in this study are some of the same families that participated in our genome-wide study (Yokouchi et al. 2000). Because we had obtained supportive evidence in our families for linkage of asthma to human chromosome $6 \mathrm{p}$, where the PAFAH gene is located, in this study we examined only the proband $(n=118)$ and parents $(n=236)$ in each family represented. For the adult control, we determined the genotypes of 188 anonymous, unrelated, healthy Japanese women. Adult control subjects were not evaluated for asthma. We selected child controls who met all of the following criteria: (1) no symptoms or history of allergic diseases, (2) no detectable dust-mite-specific $\operatorname{IgE}$ antibody, and (3) total serum IgE levels below the general population mean for their ages. The mean age of the child controls was 11 years (range, 9 to 14). This study was approved by the Committee of Ethics of the University of Tsukuba.

The genotype of the Val279Phe polymorphism was determined by a polymerase chain reaction (PCR)-based, allele-specific method described previously (Stafforini et al. 1996).

Allelic and genotypic TDTs were assessed with the SIB-PAIR program (http://www2.qimr.edu.au/davidD). A $P$ value $<0.05$ was considered statistically significant.

\section{Results}

The TDT revealed that transmission of the Phe279 allele to asthmatic children was not statistically significant: the transmitted alleles: nontransmitted alleles ratio for the Phe279 allele was 54:39 $(P=0.14)$. However, the genotypic transmission test revealed a significant deviation from expected values. Among probands, 30 were homozygous for Val279, 37 were heterozygous, and 15 were homozygous for Phe279, whereas the expected numbers were $30.2,44.0$, and 7.8, respectively $(P=0.02)$.
Table 1 shows the genotypic distribution of the Val279Phe polymorphism of the PAFAH gene. The frequency of homozygosity of the Phe279 allele was significantly higher in asthmatic children than in the parents, adult controls, or child controls. The Phe279 allele was found more frequently in asthmatic children than it was in controls. The frequency of the Phe279 allele was also increased significantly in the parents of asthmatic children compared with in the controls. There was no statistical difference in the frequency of the Phe279 allele between asthmatic children and their parents.

\section{Discussion}

In this study, we confirmed an association between the Phe279 allele of the PAFAH gene and atopic asthma through case control comparisons. Case control studies are susceptible to hidden population stratifications, and inconsistent results between studies often result from different allele or genotype frequencies in the control groups rather than in the patient groups. The prevalence of homozygosity for Phe279 in our control subjects was similar to frequencies reported for other Japanese control populations (Hiramoto et al. 1997; Satoh et al. 1999; Stafforini et al. 1999). The frequency of the Phe279 allele in the present study was also similar to frequencies reported previously. Therefore, our positive findings were not likely due to low prevalence of homozygosity for Phe279 in our control subjects. In addition, we found a significant association between Phe279 homozygosity and asthma in our families by comparing the prevalence between asthmatic children and their parents and by the results of the TDT analyses. Because homozygosity for Phe279 causes complete lack of PAFAH activity, the present study provides evidence for association between PAFAH deficiency and atopic asthma.

An association between the Val279Phe polymorphism and the severity of asthma was observed by Stafforini and colleagues (Stafforini et al. 1999) but not by Satoh and colleagues (Satoh et al. 1999). The association between ho- 
mozygosity for Phe279 and atopic asthma in the present study is supported by an odds ratio of 3.3 with controls. This may be due to the homogeneous clinical characteristics of our patients with childhood mite-sensitive atopic asthma. Linkage of asthma to chromosome $6 \mathrm{p} 21$, where the $P A F A H$ gene is located, was observed previously in our families (Yokouchi et al. 2000). It is likely that the association between the homozygosity of the Phe279 allele and asthma accounts for this linkage, at least in part.

\section{References}

Benveniste J, Roubin R, Chignard M, Jouvin-Marche E, Le Couedic JP (1982) Release of platelet-activating factor (PAF-acether) and 2-lyso PAF-acether from three cell types. Agents Actions 12:711-713

Hiramoto M, Yoshida H, Imaizumi T, Yoshimizu N, Satoh K (1997) A mutation in plasma platelet-activating factor acetylhydrolase $($ Val279 $\rightarrow$ Phe) is a genetic risk factor for stroke. Stroke 28:24172420

Hsieh KH, Ng CK (1993) Increased plasma platelet-activating factor in children with acute asthmatic attacks and decreased in vivo and in vitro production of platelet-activating factor after immunotherapy. J Allergy Clin Immunol 91:650-657

Miwa M, Miyake T, Yamanaka T, Sugatani J, Suzuki Y, Sakata S, Araki Y, Matsumoto M (1988) Characterization of serum plateletactivating factor (PAF) acetylhydrolase. Correlation between defi- ciency of serum PAF acetylhydrolase and respiratory symptoms in asthmatic children. J Clin Invest 82:1983-1991

Prescott SM, Zimmerman GA, McIntyre TM (1990) Platelet-activating factor. J Biol Chem 265:17381-17384

Satoh N, Asano K, Naoki K, Fukunaga K, Iwata M, Kanazawa M, Yamaguchi K (1999) Plasma platelet-activating factor acetylhydrolase deficiency in Japanese patients with asthma. Am J Respir Crit Care Med 159:974-979

Stafforini DM, Satoh K, Atkinson DL, Tjoelker LW, Eberhardt C, Yoshida H, Imaizumi T, Takamatsu S, Zimmerman GA, McIntyre TM, Gray PW, Prescott SM (1996) Platelet-activating factor acetylhydrolase deficiency. A missense mutation near the active site of an anti-inflammatory phospholipase. J Clin Invest 97:2784-2791

Stafforini DM, Numao T, Tsodikov A, Vaitkus D, Fukuda T, Watanabe N, Fueki N, McIntyre TM, Zimmerman GA, Makino S, Prescott SM (1999) Deficiency of platelet-activating factor acetylhydrolase is a severity factor for asthma. J Clin Invest 103:989997

Tsukioka K, Matsuzaki M, Nakamata M, Kayahara H (1993) Increased plasma levels of platelet-activating factor (PAF) and low serum PAF acetylhydrolase (PAFAH) activity in adult patients with bronchial asthma. Arerugi 42:167-171

Tsukioka K, Matsuzaki M, Nakamata M, Kayahara H, Nakagawa T (1996) Increased plasma level of platelet-activating factor (PAF) and decreased serum PAF acetylhydrolase (PAFAH) activity in adults with bronchial asthma. J Investig Allergol Clin Immunol 6:22-29

Yokouchi Y, Nukaga Y, Shibasaki M, Noguchi E, Kimura K, Ito S, Nishihara M, Yamakawa-Kobayashi $\mathrm{K}$, Takeda $\mathrm{K}$, Imoto $\mathrm{N}$, Ichikawa K, Matsui A, Hamaguchi H, Arinami T (2000) Significant evidence for linkage of mite-sensitive childhood asthma to chromosome 5q31-q33 near the interleukin $12 \mathrm{~B}$ locus by a genome-wide search in Japanese families. Genomics 66:152-160 